University of South Carolina

Scholar Commons

$3-1-2008$

\title{
Wideband Smaller Unit-Cell Planar EBG Structures and Their Application
}

\author{
M. Faisal Abedin \\ University of South Carolina - Columbia \\ Mohammed Z. Azad \\ Motorola,Inc., azad@motorola.com \\ Mohammod Ali \\ University of South Carolina - Columbia, alimo@engr.sc.edu
}

Follow this and additional works at: https://scholarcommons.sc.edu/elct_facpub

Part of the Electrical and Computer Engineering Commons

Publication Info

Published in IEEE Transactions on Antennas and Propagation, Volume 56, 2008, pages 903-908.

http://ieeexplore.ieee.org/xpl/Recentlssue.jsp?punumber=8

(C) 2008 by IEEE

This Article is brought to you by the Electrical Engineering, Department of at Scholar Commons. It has been accepted for inclusion in Faculty Publications by an authorized administrator of Scholar Commons. For more information, please contact digres@mailbox.sc.edu. 


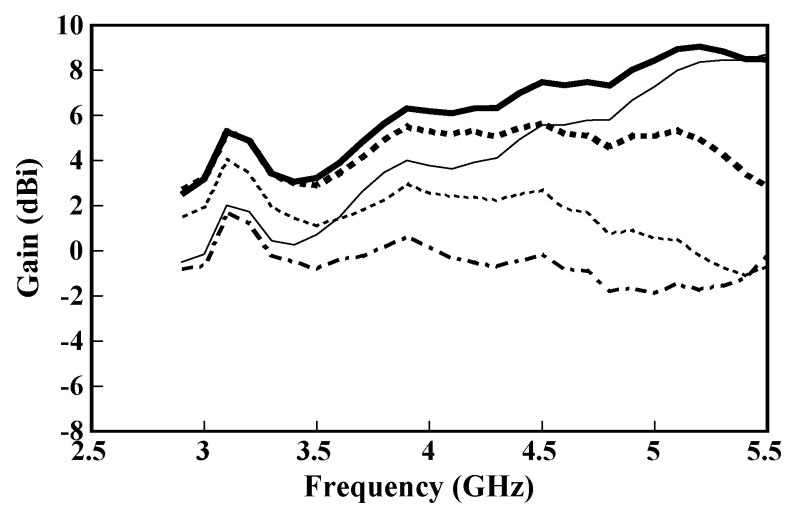

Fig. 6. Gain variations against frequency for the case of $a=52 \mathrm{~mm}$ in Table I.

$$
\begin{aligned}
& \quad \theta=15^{\circ} \longrightarrow \theta=30^{\circ} \cdots+\cdots=45^{\circ}---\theta=60^{\circ} \\
& -\theta-\theta=75^{\circ}
\end{aligned}
$$

\section{CONCLUSIONS}

The dual-band and wide-band designs for a square-ring patch antenna with four shorting walls are presented. Three resonant modes with conical radiation patterns can be excited in the proposed antenna. The key parameters which affect the resonant frequencies of the three modes are studied, and it is found that these modes can make the antenna with the dual-band or wide-band operation if the width of the shorting walls is properly selected. For the dual-band design, the experimental results show the impedance bandwidths at lower and higher operating frequencies are 42 and $8 \%$, respectively. The broad bandwidth at the lower operating frequency is due to the coupling of two resonant modes. Moreover, the two operating frequencies of the dualband antenna can be further coupled together and form a wide-band operation. Several prototypes with the wide-band operation are constructed and measured, and an impedance bandwidth of around $70 \%$ is realized. Also, the antenna can provide stable conical radiation patterns within the obtained impedance bandwidth. Therefore, the proposed designs are suitable for the applications of the present wireless communications.

\section{REFERENCES}

[1] M. J. Ammann and Z. N. Chen, "A wide-band shorted planar monopole with bevel,” IEEE Trans. Antennas Propag., vol. 51, pp. 901-903, Apr. 2003.

[2] J. Y. Jan and T. M. Kuo, "CPW-fed wideband planar monopole antenna for operations in DCS, PCS, 3G, and Bluetooth," Electron. Lett., vol. 41, pp. 991-993, Sep. 1, 2005.

[3] Y. F. Liu, K. L. Lau, Q. Xue, and C. H. Chan, "Experimental studies of printed wide-slot antenna for wide-band applications," IEEE Antennas Wireless Lett., vol. 3, pp. 273-275, 2004.

[4] Y. X. Guo, M. Y. W. Chia, Z. N. Chen, and K. M. Luk, "Wide-band L-probe fed circular patch antenna for conical-pattern radiation," IEEE Trans. Antennas Propag., vol. AP-52, pp. 1115-1116, Apr. 2004.

[5] Y. S. Wu and F. J. Rosenbaum, "Mode chart for microstrip ring resonators," IEEE Trans Microw. Theory Tech., vol. MTT-21, pp. 487-489, Jul. 1973.

[6] C. Delaveaud, P. Leveque, and B. Jecko, "New kind of microstrip antenna: The monopolar wire-patch antenna," Electron. Lett., vol. 30, pp. 1-2, Jan. 6, 1994.

[7] K. W. Chan, K. F. Tong, and K. M. Luk, "Wideband circular patch antenna operated at $\mathrm{TM}_{01}$ mode," Electron. Lett., vol. 35, pp. 2070-2071, Nov. 25, 1999

[8] J. S. Row and S. W. Wu, "Monopolar square patch antennas with wideband-operation," Electron. Lett., vol. 42, pp. 139-140, Feb. 2, 2006.

\section{Wideband Smaller Unit-Cell Planar EBG Structures and Their Application}

\author{
M. F. Abedin, M. Z. Azad, and M. Ali
}

\begin{abstract}
A new low-cost smaller unit-cell planar electromagnetic bandgap (EBG) structure operating at the lower $\mathbf{G H z}$ frequencies (below $6 \mathrm{GHz}$ ) is proposed. EBG structures based on this new geometry are designed on a number of commonly available substrates. Characteristics of such structures, such as bandgap and reflection phase profile are analyzed. A simple empirical model is proposed to predict the surface wave stopband frequency of the proposed EBG structure. Finally, a low-profile dipole antenna is designed and tested for operation on the EBG structure.
\end{abstract}

Index Terms-Electromagnetic bandgap (EBG), antenna, planar, wireless.

\section{INTRODUCTION}

In recent years, there has been a growing interest on electromagnetic bandgap (EBG) structures to design low profile high-performance antennas for wireless applications [1]-[17]. Such structures have attracted a great deal of interest among researchers due to their ability to influence the propagation of electromagnetic waves. The primary attribute of an EBG structure is its bandgap characteristic, which can be defined by its surface wave and reflection phase characteristics. The periodicity of the structure is responsible for the above. The efficiency of a printed antenna can be significantly improved through surface wave suppression achieved by integration of EBG structures [1]-[10]. Moreover, surface wave suppression can also reduce antenna mutual coupling [11], [12]. As indicated earlier the reflection phase properties of an EBG structure can be exploited to design extremely low profile directional antennas [12]-[17].

The bandgap characteristic of any specific EBG structure is dependent upon the dielectric constant and thickness of the substrate material as well as the EBG geometry. During the early phases of research on EBG structures most studies were focused on three-dimensional geometries [1], [11], [18]-[22]. An example of a low frequency $(<6 \mathrm{GHz})$ EBG structure consisting of 3-layers of polyimide and FR4 can be found in [1]. The 3-layer construction technique increases the complexity of manufacturing. Lately researchers have focused on planar EBG structures, one of which is the UCEBG (unipanar compact EBG) structure [3]-[5] with reported stopbands at or above $10 \mathrm{GHz}$ using high dielectric constant substrates, such as Duroid 6010. However, stopband at a lower frequency can be easily obtained with a larger unit cell size and hence more board space and increased cost, which is generally undesirable. Clearly there is a need to design low cost smaller unit cell planar EBG structures that operate below $6 \mathrm{GHz}$ to meet the demands of applications, such as mobile phone, GPS, and WLAN. Recently various smaller EBG structures have been developed as reported in [23], [24].

In this paper, we propose a smaller unit-cell planar EBG geometry with no via holes that can operate in the lower $\mathrm{GHz}$ frequencies $(<6 \mathrm{GHz})$. We also introduce a simple empirical model to design such EBG structures and design and fabricate a thin dipole antenna and EBG with directional characteristics. We focus on reducing the cost

Manuscript received March 24, 2006; revised July 26, 2007. This work was supported in part by the National Science Foundation (NSF) Career Award ECS0237783.

The authors are with the Department of Electrical Engineering, University of South Carolina, Columbia, SC 29208 USA (e-mail: alimo@engr.sc.edu).

Digital Object Identifier 10.1109/TAP.2008.917007 


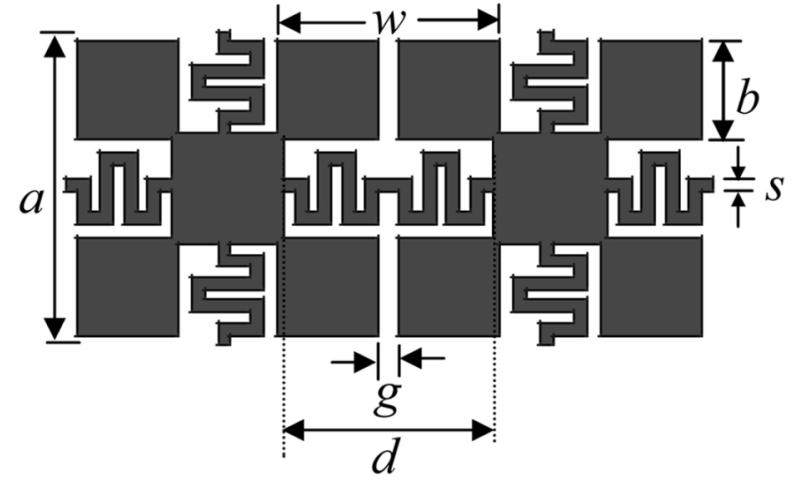

Fig. 1. Two unit cells of our proposed planar EBG structure.

of planar EBGs by considering low-cost low-dielectric substrates. The EBG structure introduced achieves lower stopband frequency of operation with the help of meandered connecting branches which provide high inductance values. The surface wave bandgap achieved using this new structure is considerably wider than that can be achieved using the existing UCEBG structure.

This paper is organized as follows. In Section II, the design of the proposed planar EBG structure is introduced. The band-gap features on Duroid 6010 and TMM substrates are discussed in Section III. In Section IV an empirical model which can be used to predict the surface wave stopband frequency is proposed. In Section V the reflection phase characteristics of the EBG structure are studied and in Section VI a thin $(0.02 \lambda)$ directional dipole antenna is developed for operation at around $1.9 \mathrm{GHz}$ on the proposed EBG structure.

\section{LOWER GHz FreQUENCY PlANAR-EBG STRUCTURE}

The geometry of our proposed smaller unit-cell planar EBG structure is shown in Fig. 1. The geometry was printed on one side of a dielectric substrate. To study the EBG characteristics a microstrip transmission line with $50 \Omega$ characteristic impedance was printed on the opposite side of the EBG. Photographs of a fabricated structure is shown in Fig. 2. Each unit cell consists of four square metal pads and four meandered connecting branches all of which are held together at the center by a central square metal pad. The meandered connecting branches provide the inductance $L$ and the square pads provide the capacitance $C$ both of which determine the stopband frequency of the structure. To achieve a stopband at a lower frequency higher inductance and/or capacitance values are needed.

\section{SURFACE WAVE Stopband}

Simulations of our proposed EBG structure were conducted using IE3D. The simulation model consisted of a planar array of 3 by 6 unit cells on top of a dielectric substrate. The substrate was considered infinite. Prototypes of the proposed EBG structure were also fabricated and tested on Duroid $6010\left(\varepsilon_{r}=10.2, \tan \delta=0.0023\right)$ and TMM $\left(\varepsilon_{r}=4.5, \tan \delta=0.002\right)$ substrates with various thicknesses. To measure the transmission across the EBG structure and determine its surface wave stopband frequency the inner conductors of two SMA connectors were soldered to the two ends of the microstrip line. The ground conductors of the connectors on the EBG side of the substrate were soldered to the EBG structure itself.

\section{A. On Duroid 6010, a $=480$ Mils}

The first EBG geometry was simulated and fabricated on a 25-mil thick Duroid 6010 substrate $\left(\varepsilon_{r}=10.2, \tan \delta=0.0023\right)$. The width
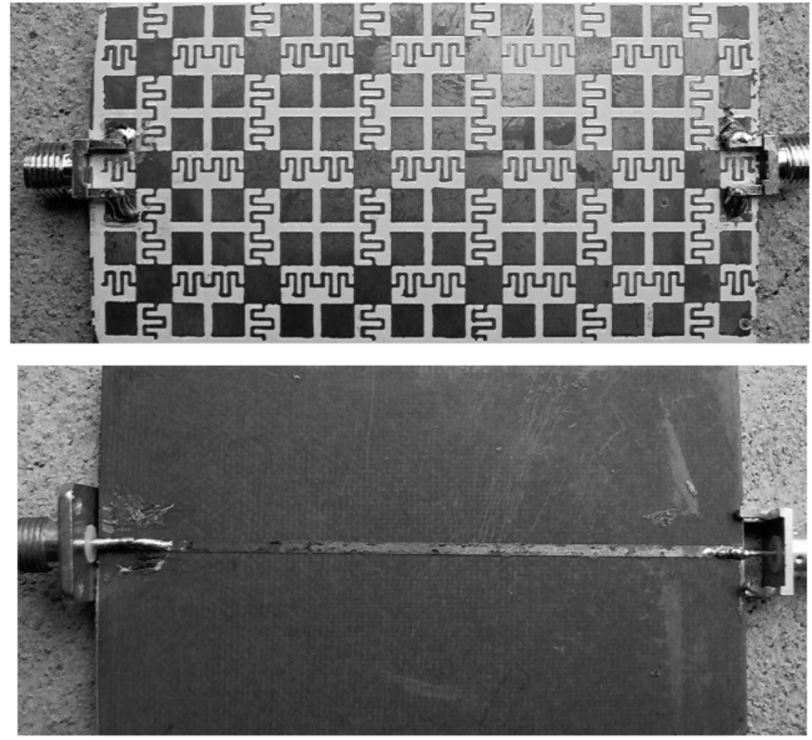

Fig. 2. Photographs of a fabricated EBG structure, top and bottom views.

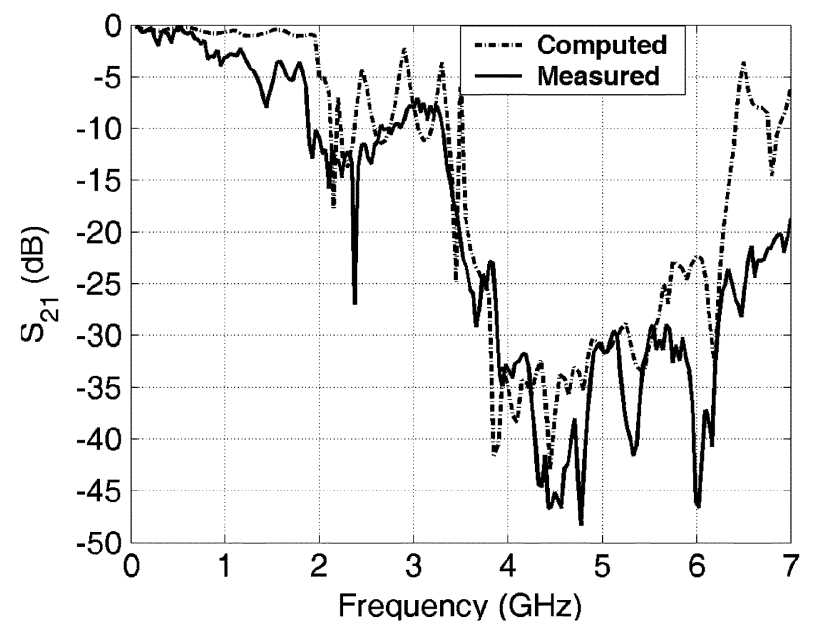

Fig. 3. $\mathrm{S}_{21}(\mathrm{~dB})$ data of a 480 mil unit-cell EBG on 25 mil thick Duroid 6010 substrate $\left(\varepsilon_{r}=10.2\right.$, $\left.\tan \delta=0.0023\right)$. Other parameters: $b=150$ mils, $s=20$ mils, $g=30$ mils, $w=330$ mils and $d=310$ mils.

of the $50 \Omega$ microstrip transmission line was 24 mils. Other EBG parameters were: $b=150$ mils, $s=20$ mils, $g=30$ mils, $w=330$ mils and $d=310$ mils. Fig. 3 shows the computed $\mathrm{S}_{21}(\mathrm{~dB})$ data. A clear stopband is observed between $3.8-5.6 \mathrm{GHz}$, where the insertion loss $\left(\mathrm{S}_{21}\right)$ is lower than $30 \mathrm{~dB}$. Corresponding measured data for our proposed EBG structure are also shown in Fig. 3.

The measured data are in good agreement with the simulated data in terms of predicting the EBG stopband, its loss characteristic and frequency span. For comparison a UCEBG structure (shown as inset in Fig. 4) with the same cell size and on the same Duroid 6010 substrate was also simulated and measured. These results are shown in Fig. 4. The simulated data reveals a narrow stopband (3.6\%) around $8 \mathrm{GHz}$. The measured data proves the existence of a narrow stopband $(3.7 \%)$ around $8 \mathrm{GHz}$. Clearly compared to the existing UCEBG structure our proposed EBG with the same unit cell-size and on the same substrate reduces the stopband frequency by a factor of two. In addition the frequency span of the stopband for our proposed EBG structure is much wider (37\% compared to $4 \%$ ) than that of the UCEBG structure. Given the size constraints in mobile handheld wireless devices 


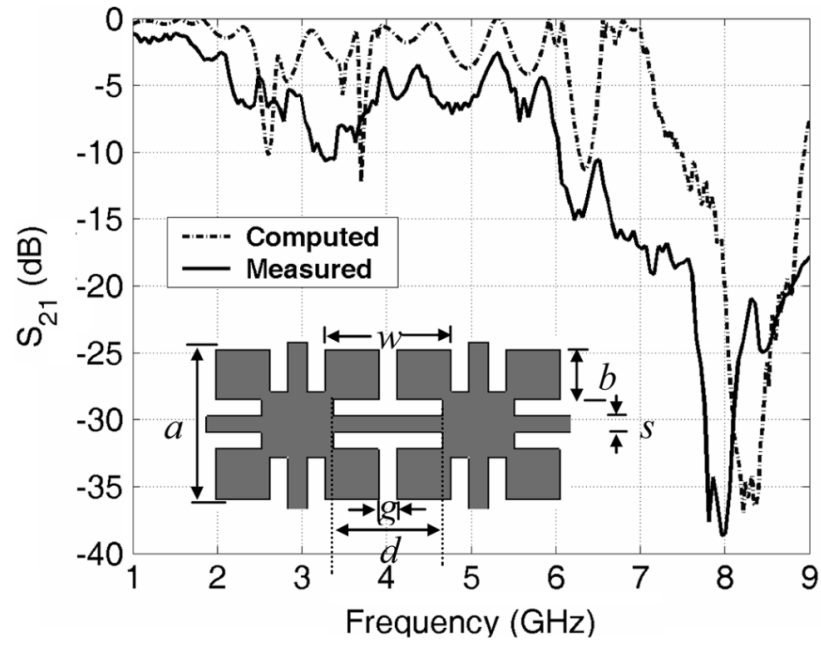

Fig. 4. $\mathrm{S}_{21}(\mathrm{~dB})$ data of a 480 mil unit-cell UCEBG structure on a 25 mil thick Duroid 6010 substrate $\left(\varepsilon_{r}=10.2, \tan \delta=0.0023\right)$. Other parameters: $b=$ 150 mils, $s=20$ mils, $g=30$ mils, $w=330$ mils and $d=310$ mils.

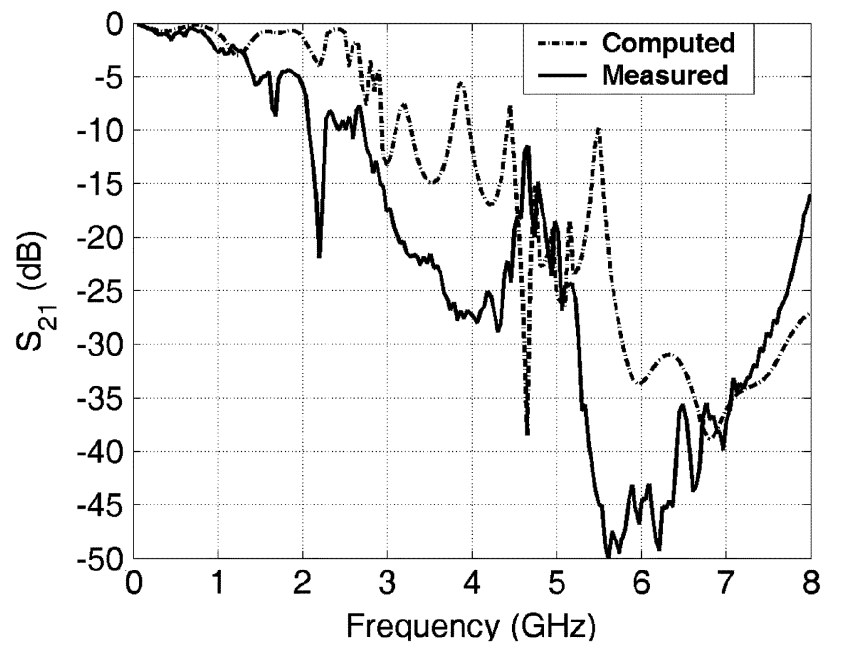

Fig. 5. $\mathrm{S}_{21}(\mathrm{~dB})$ data of a 480 mil unit-cell EBG on 25 mil thick TMM substrate $\left(\varepsilon_{r}=4.5, \tan \delta=0.002\right)$. Other parameters: $b=150$ mils, $s=20$ mils, $g=30$ mils, $w=330$ mils and $d=310$ mils.

smaller unit-cell planar EBG structures that can operate at lower frequencies are desirable. Wide stopbands are also of interest to reduce the cross-talk between transmission lines of a computer circuit board [25].

\section{B. On TMM, Unit Cell Size, $\mathrm{a}=480 \mathrm{Mils}$}

A similar EBG structure was also modeled, fabricated and tested on a 25 mil thick TMM substrate $\left(\varepsilon_{r}=4.5, \tan \delta=0.002\right)$. This substrate is cheaper than the high dielectric constant Duroid 6010. The EBG unit cell size was 480 mils and the other parameters were: $b=150$ mils, $s=20$ mils, $g=30$ mils, $w=330$ mils and $d=310$ mils. Fig. 5 shows the computed and measured $S_{21}(\mathrm{~dB})$ data. A clear stopband is observed between the frequency range of 5.5 to $7.7 \mathrm{GHz}$. The stopband frequency coincides with the unlicensed wireless local area network (WLAN) bands from 5 to $6 \mathrm{GHz}$.

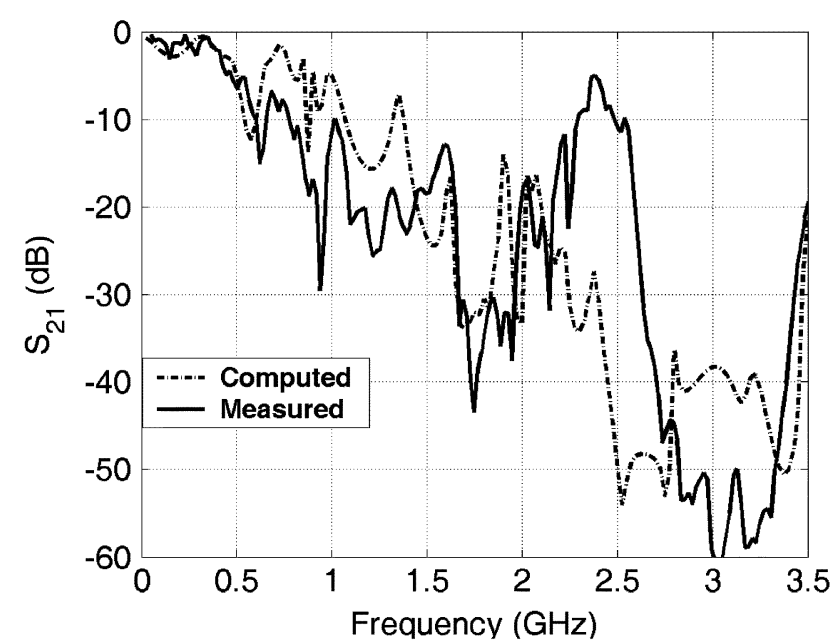

Fig. 6. $\mathrm{S}_{21}(\mathrm{~dB})$ data of a 920 mil unit-cell EBG structure on 25 mil thick TMM substrate $\left(\varepsilon_{r}=4.5, \tan \delta=0.002\right)$. Other parameters: $b=300$ mils, $s=20$ mils, $g=20$ mils, $w=620$ mils and $d=600$ mils.

\section{On TMM; Unit Cell Size, $\mathrm{a}=920$ Mils}

There are many commercial and defense wireless applications (mobile phones, GPS, WLAN, JTRS) where compact planar EBG structures operating below $3 \mathrm{GHz}$ are required to develop miniaturized, ultra-thin, directional antennas and antenna arrays. To achieve a stopband frequency lower than $3 \mathrm{GHz}$ a planar EBG structure with 920 mil unit-cell size was investigated on a 25 mil thick TMM substrate. An EBG matrix consisting of 3 by 6 unit cells was considered. Other EBG parameters were as follows: $b=300$ mils, $s=20$ mils, $g=20$ mils, $w=620$ mils and $d=600$ mils. Computed $S_{21}(\mathrm{~dB})$ data of this structure are shown in Fig. 6. It is apparent that the stopband frequency of this EBG structure is from $2.5 \mathrm{GHz}$ to $3.5 \mathrm{GHz}$. The corresponding measured data shown in Fig. 6 validates the simulation data. The surface wave stopband characteristics of the EBGs can be used to reduce the mutual coupling between the elements of an array antenna [11], [12].

\section{Empirical Model of OUR Proposed Planar EBG Structure}

The stopband frequency of our proposed EBG structure is a function of the inductance, $L$ resulting from the meandered connecting branches and the capacitance, $C$ resulting from the spacing between the adjacent patches. We made an attempt to develop an empirical relationship between the geometrical parameters of the EBG and its surface wave stopband frequency. The empirical model developed is based on simple inductance and capacitance calculation as described below.

The inductance of a straight conductor can be calculated as [26]

$$
L=50 \times 10^{-4} d\left[\ln \left(\frac{d}{s}\right)+0.2235\left(\frac{s}{d}\right)+1.193\right] k \cdots
$$

where $d$ and $s$ are the length and width of the conductor, $t$ is the substrate thickness and $k$ is a correction factor to account for the ground plane and is given by

$$
k=0.57-0.145 \ln \left(\frac{s}{t}\right) .
$$

Here all dimensions are in mils and the inductance is in nano-Henry (nH). For a UCEBG structure since each unit cell consists of four axial 
TABLE I

COMPARISON OF COMPUTED, MEASURED AND EMPIRICAL SURFACE-WAVE STOP-BAND FREQUENCIES OF OUR PROPOSED PlanAR EBG STRUCTURES; $s=20, t=25$ MILS

\begin{tabular}{|c|c|c|c|c|c|c|c|c|}
\hline $\boldsymbol{a}$ & $\boldsymbol{b}$ & $\boldsymbol{g}$ & $\boldsymbol{w}$ & $\boldsymbol{d}$ & Substrate & $\begin{array}{c}\text { IE3D } \\
(\mathbf{G H z})\end{array}$ & $\begin{array}{c}\text { Measured } \\
(\mathbf{G H z})\end{array}$ & $\begin{array}{c}\text { Empirical } \\
(\mathbf{C e n t e r}) \\
(\mathbf{G H z})\end{array}$ \\
\hline 480 & 150 & 30 & 330 & 310 & Duroid 6010 & 4.2 & 4.15 & 4.4 \\
\hline 480 & 150 & 30 & 330 & 310 & TMM & 6.25 & 6.4 & 6.2 \\
\hline 620 & 200 & 20 & 420 & 400 & TMM & 3.95 & 3.65 & 4.1 \\
\hline 920 & 300 & 20 & 620 & 600 & TMM & 2.95 & 3.0 & 2.5 \\
\hline
\end{tabular}

narrow branches connected at the center, the total inductance for each unit cell is a parallel equivalent of four inductors $(L)$, which is given by

$$
L=12.5 \times 10^{-4} d\left[\ln \left(\frac{d}{s}\right)+0.2235\left(\frac{s}{d}\right)+1.193\right] k \cdots .
$$

In order to account for the increase in inductance contributed by the meandered branches of our proposed EBG structure we modify (2) as follows:

$$
L=25 \times 10^{-4} d\left[\ln \left(\frac{d}{s}\right)+0.2235\left(\frac{s}{d}\right)+1.193\right] k \cdots
$$

The edge capacitance between two adjacent plates of width $b$ and gap $g$ is given by [1]

$$
C=\frac{25 b \varepsilon_{0}\left(\varepsilon_{r 1}+\varepsilon_{r 2}\right)}{\pi} \cosh ^{-1}\left(\frac{w}{g}\right) \cdots
$$

where the plates are supported by a substrate with dielectric constant, $\epsilon_{r 1}$ on one side and are covered by a substrate with dielectric constant $\epsilon_{r 2}$ on the other. All dimensions are in mils.

The total edge capacitance for each unit cell is the parallel equivalent of two capacitors (C), as given by

$$
C=\frac{50 b \varepsilon_{0}\left(\varepsilon_{r 1}+\varepsilon_{r 2}\right)}{\pi} \cosh ^{-1}\left(\frac{w}{g}\right) \cdots .
$$

Finally, the surface wave stopband frequency is computed as

$$
f=\frac{1}{2 \pi \sqrt{L C}} \cdots
$$

Stopband center frequencies obtained from IE3D simulations, experimental measurements and from the empirical model are compared in Table I. The geometrical parameters of the EBG structures are also listed in the Table. The empirically determined surface wave stopband center frequencies in most of the cases are close to the frequencies obtained from full-wave simulation and measurement. Also since the span of the stopband is as wide as $37 \%$ the slight error in the empirical results will not create significant shift in design frequency.

\section{Reflection Phase Characteristics}

In low-profile printed antenna applications the surface wave stopband of EBGs is not the only property of interest since electromagnetic waves are not restricted to propagate exclusively in the horizontal plane
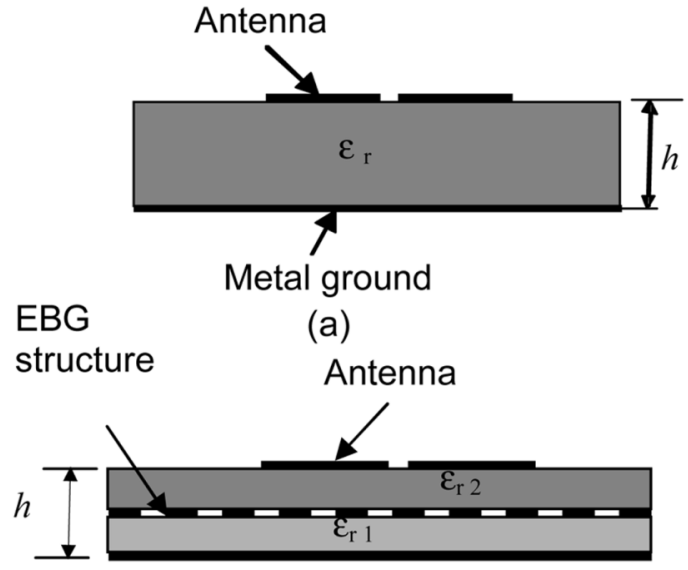

(b)

Fig. 7. Dipole antenna (a) on a grounded dielectric substrate and (b) on an EBG structure.

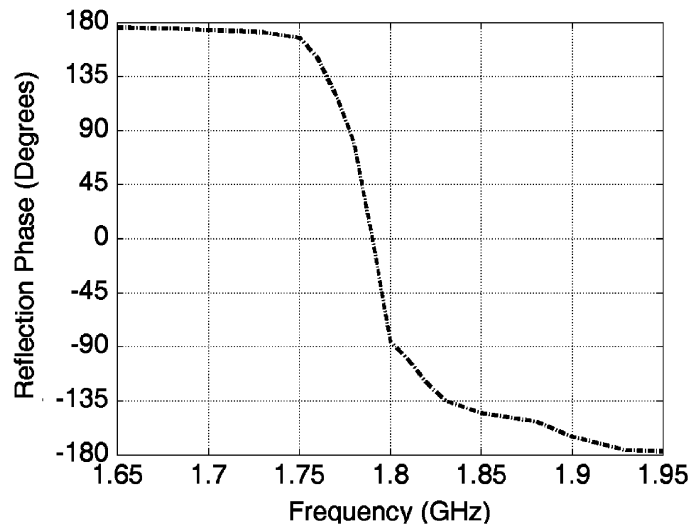

Fig. 8. Computed reflection phase profile of a 920 mil unit cell EBG structure on 25 mil thick TMM substrate $\left(\varepsilon_{r}=4.5, \tan \delta=0.002\right)$. Other parameters: $b=300$ mils, $s=20$ mils, $g=20$ mils, $w=620$ mils and $d=600$ mils.

over the dielectric substrate. Instead a more complicated interaction occurs. In order to achieve good return loss and high efficiency low profile antennas are generally placed horizontally close to an EBG surface [see Fig. 7(b)] which is designed in such a manner that the EBG reflection phase stopband generally coincides with the operating frequency band of the antenna [14], [15]. Therefore, determining the reflection phase characteristics is also important to design low-profile antennas.

An HFSS model described in [16] with periodic boundary conditions was used to compute the EBG reflection phase data. The computed reflection phase data of the 920-mil unit-cell EBG structure are shown in Fig. 8, where the frequency corresponding to the zero degree reflection phase is $1.8 \mathrm{GHz}$. It is observed that the phase profile slopes down from $160^{\circ}$ to $-160^{\circ}$ within a frequency span of 1.75 to $1.85 \mathrm{GHz}$. Note that the surface wave bandgap $(2.5-3.5 \mathrm{GHz})$ of the same structure is quite different (see Fig. 5). The surface wave bandgap is important to eliminate or suppress surface waves while the reflection phase stopband is important to design extremely low profile printed antennas.

\section{APPLICATION}

Based on our previous experience with low-profile antennas on EBG structures [15] we made an attempt to investigate the characteristics of 

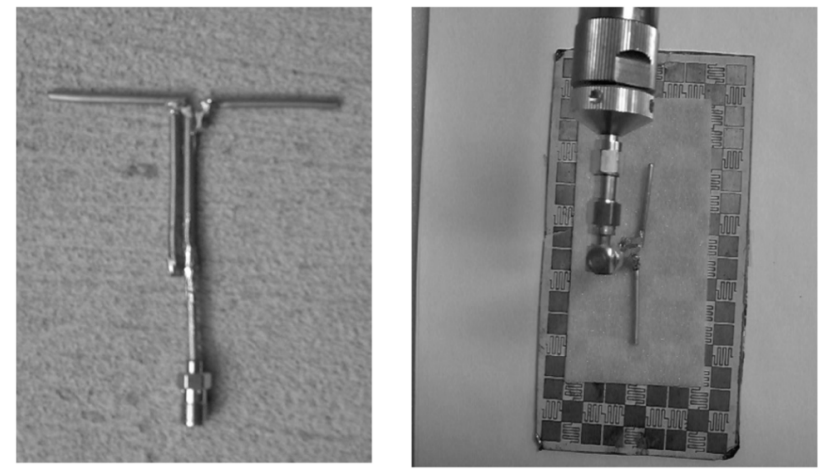

Fig. 9. Photographs of the dipole prototype and the $S_{11}$ measurement setup.

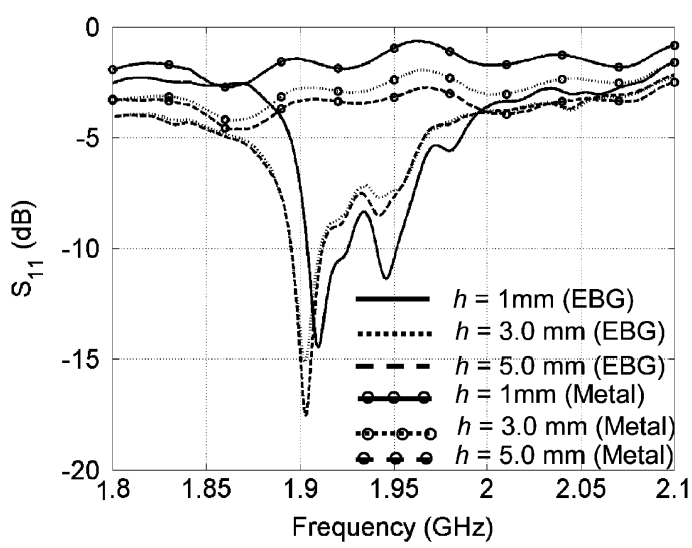

Fig. 10. Measured $\mathrm{S}_{11}$ data of dipole.

loss characteristics only antenna heights of $3 \mathrm{~mm}$ or higher results in positive gain. At $1.92 \mathrm{GHz} 1.2 \mathrm{dBi}$ of peak gain is probably adequate for most mobile device applications. The EBG provides an additional advantage of directionality. If higher gain is required an array will be the preferred choice. Since the dipole is essentially a one dimensional structure (disregarding its width) compared to a microstrip patch antenna an array with the same size can accommodate more dipole elements than patches. This advantage is even more important for wireless handheld terminals, such as phones, laptops and PDAs. Thin directional antennas or antennas arrays will significantly enhance the performance or capacity of such devices. At present it is not easy to accommodate EBG structures inside wireless phones and laptops since space availability in these devices is very limited. Nevertheless tremendous potential does exist for EBG assisted ultra-thin directional radiators for commercial applications.

\section{CONCLUSION}

The EBG structure introduced here reduces the transmission or surface wave stopband frequency by a factor of two compared to a conventional UCEBG structure when fabricated with the same unit cell size and on the same substrate. Our proposed structure also provides a wider surface wave stopband and larger attenuation than the conventional one. An empirical model of our proposed EBG structure has been developed to predict the surface wave stopband frequency, which gives reasonably good results for Duroid 6010 and TMM substrates. A 920 mil unit-cell EBG structure on a 25 mil thick TMM substrate demonstrates in-phase reflection feature in the lower $\mathrm{GHz}(1.8 \mathrm{GHz})$ frequency range making it directly suitable for commercial wireless applications. The in-phase reflection feature of our proposed planar EBG is demonstrated by developing a thin directional $(0.02 \lambda)$ cylindrical dipole antenna.

\section{REFERENCES}

[1] D. F. Sievenpiper, "High impedance electromagnetic surfaces," Ph.D. dissertation, University of California, Los Angeles, 1999.

[2] H. D. Yang, N. G. Alexopoulos, and E. Yablonovitch, "Photonic band-gap materials for high-gain printed circuit antennas," IEEE Trans. Antennas Propag., vol. 45, no. 1, pp. 185-187, Jan. 1997.

[3] R. Coccioli, F. R. Yang, K. P. Ma, and T. Itoh, "Aperture-coupled patch antenna on UC-PBG substrate," IEEE Trans. Microw. Theory Tech. vol. 47, pp. 2123-2130, Nov. 1999.

[4] M. Rahman and M. Stuchly, "Wide-band microstrip patch antenna with planar PBG structure," in Proc. IEEE AP-S Int. Symp. Dig., Jul. 2001, vol. 2, pp. 486-489.

[5] S. Sharma and L. Shafai, "Enhanced performance of an aperture-coupled rectangular microstrip antenna on a simplified uniplanar compact photonic bandgap (UCPBG) structure," in Proc. IEEE AP-S Int. Symp. Dig., Jul. 2001, vol. 2, pp. 498-501. 
[6] J. S. Colburn and Y. Rahmat-Samii, "Patch antennas on externally perforated high dielectric constant substrates," IEEE Trans. Antennas Propag., vol. 47, pp. 1785-1794, Dec. 1999.

[7] R. F. J. Broas, D. F. Sievenpiper, and E. Yablonovitch, "A high-impedance ground plane applied to a cell-phone handset geometry," IEEE Trans. Microw. Theory Tech., vol. 49, no. 7, pp. 1262-1265, Jul. 2001.

[8] F. Yang and Y. Rahmat-Samii, "Mutual coupling reduction of microstrip antennas using electromagnetic band-gap structure," in Proc. IEEE AP-S Int. Symp. Dig., Jul. 2001, vol. 2, pp. 478-481.

[9] R. Gonzalo, P. de Maagt, and M. Sorolla, "Enhanced patch-antenna performance by suppressing surface waves using photonic-bandgap substrates," IEEE Trans. Microw. Theory Tech., vol. 47, no. 11, pp. 2131-2138, Nov. 1999.

[10] Y. J. Park, A. Herschlein, and W. Wiesbeck, "A photonic bandgap (PBG) structure for guiding and suppressing surface waves in millimeter-wave antennas," IEEE Trans. Microw. Theory Tech., vol. 49, no. 10 , pp. 1854-1859, Oct. 2001.

[11] F. Yang and Y. Rahmat-Samii, "Microstrip antennas integrated with electromagnetic band-gap (EBG) structures: A low mutual coupling design for array applications," IEEE Trans. Antennas Propag., vol. 51, pp. 2939-2949, Oct. 2003.

[12] M. F. Abedin and M. Ali, "Effects of a smaller unit cell planar EBG structure on the mutual coupling of a printed dipole array," IEEE Antennas Wireless Propag. Lett., vol. 4, pp. 274-276, 2005.

[13] F. Yang and Y. Rahmat-Samii, "A low profile circularly polarized curl antenna over electromagnetic band-gap (EBG) surface," Microw. Opt. Tech. Lett., vol. 31, no. 4, pp. 478-481, Nov. 2001.

[14] F. Yang and Y. Rahmat-Samii, "Reflection phase characterizations of the EBG ground plane for low profile wire antenna applications," IEEE Trans. Antennas Propag., vol. 51, no. 10, pp. 2691-2703, Oct. 2003.

[15] M. F. Abedin and M. Ali, "Effects of EBG reflection phase profiles on the input impedance and bandwidth of ultra-thin directional dipoles," IEEE Trans. Antennas Propag., vol. 53, no. 11, pp. 3664-3672, Nov. 2005.

[16] M. F. Abedin and M. Ali, "A low profile dipole antenna backed by a planar EBG structure," in Proc. IEEE Int. Workshop on Antenna Tech., Small Antennas and Novel Metamaterials, Mar. 6-8, 2006, pp. 13-16.

[17] Z. Li and Y. Rahmat-Samii, "PBG, PMC and PEC ground planes: A case study of dipole antennas," in Proc. IEEE AP-S Int. Symp. Dig., Jul. 2000, vol. 2, pp. 674-677.

[18] D. Sievenpiper, J. Schaffner, B. Loo, G. Tangonan, R. Harold, J. Pikulski, and R. Garcia, "Electronic beam steering using a varactortuned impedance surface," in Proc. IEEE AP-S Int. Symp. Dig., Jul. 2001, vol. 1, pp. 174-177.

[19] D. Sievenpiper, L. Zhang, R. F. J. Broas, N. G. Alexopolous, and E. Yablonovitch, "High impedance electromagnetic surfaces with a forbidden frequency band," IEEE Trans. Microw. Theory Tech., vol. 47, no. 11, pp. 2059-2074, Nov. 1999.

[20] Y. J. Lee, J. Yeo, R. Mittra, and W. S. Park, "Application of electromagnetic bandgap (EBG) superstrates with controllable defects for a class of patch antennas as spatial angular filters," IEEE Trans. Antennas Propag., vol. 53, no. 1, pp. 224-235, Jan. 2005.

[21] H. Mosallaei and K. Sarabandi, "A compact wide-band EBG structure utilizing embedded resonant circuits," IEEE Antennas Wireless Propag. Lett., vol. 4, pp. 5-8, 2005.

[22] J. M. Bell and M. F. Iskander, "A low-profile archimedian spiral antenna using an EBG ground plane," IEEE Antennas Wireless Propag. Lett., vol. 3, pp. 223-226, 2004.

[23] S. Tse, B. S. Isquierdo, J. C. Bachelor, and R. J. Langley, "Reduced sized cells for electromagnetic bandgap structures," Electron. Lett., vol. 39, no. 24, pp. 1699-1701, Nov. 2003.

[24] O. Folayan and R. J. Langley, "Wideband reduced size electromagnetic bandgap structure," Electron. Lett., vol. 41, no. 20, pp. 1099-1100, Sep. 2005.

[25] S. Shahparnia and O. M. Ramahi, "Electromagnetic interference (EMI) reduction from printed circuit boards (PCB) using electromagnetic bandgap structures," IEEE Trans. Electromagn. Compat., vol. 46, pp. 580-587, Nov. 2004.

[26] I. J. Bahl and P. Bhartia, Microwave Solid State Circuit Design. New York: Wiley, 1988.

\section{Experimental Analysis of a Wideband Adaptive-MIMO Antenna}

Daniele Pinchera, Jon W. Wallace, Marco Donald Migliore, and Michael A. Jensen

\begin{abstract}
An experimental measurement campaign to investigate the wideband performance of an adaptive multiple-input multiple-output (AdaM) antenna consisting of two active and six parasitic antenna elements. The measurements are conducted over a $30 \mathrm{MHz}$ bandwidth at a center frequency of $2.55 \mathrm{GHz}$ and in a variety of locations in an indoor environment. The system uses a traditional two-element array at the transmitter and either a two-element traditional array or the AdaM antenna at the receiver. The results show that compared to the traditional array, the AdaM receive antenna can achieve the same throughput with an average power reduction of $2.7 \mathrm{~dB}$ and a maximum power reduction of $7.7 \mathrm{~dB}$. The analysis further shows that the parasitic configuration works well over the entire frequency band, although improved power reduction can be obtained when the operation bandwidth is limited.
\end{abstract}

Index Terms-Broadband communication, multiple-input multipleoutput (MIMO) systems, parasitic antennas.

\section{INTRODUCTION}

Multiple-input multiple-output (MIMO) technology [1], [2] shows considerable promise as an approach for increasing the spectral efficiency of wireless communication. Because of this potential, significant research effort has been devoted to this topic, resulting in remarkably rapid evolution of the technology into emerging commercial standards and products.

As the technology transitions from the research laboratory to commercial products, efforts are focused on finding ways to effectively implement MIMO communication using simple, robust, and inexpensive system components which can fit within constrained volumes. Efforts to reduce the number of required transmit or receive electronic sub-systems (which can be expensive in terms of cost and battery power) have demonstrated that antenna selection algorithms can provide high performance under many circumstances [3], although implementation of this concept requires the addition of high-performance microwave switches and effective compensation techniques for the changing impedance of the driven elements due to coupling with adjacent elements for compact devices.

Recently solutions based on reconfigurable antenna systems have been proposed [4]-[8] which provide power gains comparable those offered by antenna selection but with a reduced set of transmit or receive electronic chains. This kind of antenna, specifically designed to work in MIMO communication systems, will thus be referred to as "MIMO antennas." In particular in [8] antenna pattern reconfiguration is achieved by adapting the loads on passive antenna elements adjacent to the driven elements. To date, this adaptive MIMO (AdaM) antenna structure has been analyzed only for a limited set of narrowband measurements.

Manuscript received December 31, 2006; revised November 5, 2007. This work was supported in part by the Italian Ministry of University (MIUR) under a Program for the Development of Research of National Interest (PRIN Grant \#2007APSKNA_001).

D. Pinchera and M. D. Migliore are with the DAEIMI, University of Cassino, 03043 Cassino, Italy (e-mail: mdmiglio@unicas.it).

M. A. Jensen is with ECEN, Brigham Young University, Provo, UT 84602 USA.

J. W. Wallace is with Jacobs University Bremen, 28759 Bremen, Germany.

Digital Object Identifier 10.1109/TAP.2008.917008 